\title{
IELTS Writing Test: Improving Cardinal Test Criteria for the Bangladeshi context
}

\author{
S M Akramul Kabir \\ University of Canterbury, New Zealand
}

\begin{abstract}
International English Language Testing System (IELTS) has become a widely used and globally accepted test for non-natives. It is conducted at more than a thousand centres in at least 130 countries (British Council, 2016), including 12 centres in Bangladesh ("Take IELTS test in or nearby Dhaka", 2018). It also encompasses all four independent skills of the English language. Due to its popularity and effectiveness as a test, it is important to focus on assessment procedures of IELTS Writing tasks in the Bangladeshi context which is inconsistent with cardinal test issues. Thus, this article provides critical commentary on the IELTS writing test based on five cardinal issues for a proper test: reliability,validity, practicality, authenticity, and washback in connection with Bangladeshi as well as other similar ESL contexts. The documentary analysis of this article may help further research to enhance the utility of the IELTS writing test to measure ESL writing competence in a global context as an international test.
\end{abstract}

Keywords: IELTS writing, test criteria, World Englishes, Bangladeshi context, ESL context

\section{Introduction}

At present, IELTS is one of the widely accepted tests for measuring English proficiency. The standard set by the test has an enormous impact on the professional and academic lives of myriads. IELTS made its inception in 1989 by substituting English Language Testing Service (ELTS), which was prevalent from 1980 to 1989. Previously, ELTS replaced English Proficiency Test Battery (EPTB) that was in operation since the mid-1960s as the British Council used to operate this test internationally to filter international applicants for the academic institutions in the UK (Charge \& Taylor, 1997). Nowadays, United Kingdom, Australia, and New Zealand recognize the IELTS as a mandatory language requirement for the entry to courses in higher education, to undertake work experience or vocational programmes as well as for immigration purposes to these countries. According to IELTS test-takers' performance report (2016a), 80.7\% people take Academic IELTS module and $19.3 \%$ people take the General Training Module. More than 2.2 million people participated in the IELTS test in the year 2013 that represents 11\% growth globally than over the previous year (British Council, 2016). 


\section{Importance of IELTS Test in the Bangladeshi Context}

Since its inception, the IELTS test is designed to focus on Communicative Language Teaching (CLT) and English for Specific Purpose (ESP) approach of English learning so that test tasks can measure testtakers' ability to use language both in academic contexts and in intended real-life situations in all four skills of language (Matin, 2014). In Bangladesh, IELTS started gaining popularity since the late1990s and about 15,000 to 20,000 candidates sit the IELTS test every year (Kar, 2013). People in Bangladesh prepare themselves to sit for IELTS for their global education and employment opportunities. IELTS results can open doors for people to study in the anglophone countries, such as USA, UK, Australia, New Zealand or to obtain a visa to live and work in those places. As a result, the number of IELTS test participants has increased rapidly not only in Bangladesh but also in other ESL and EFL countries around the world (British Council, 2016).

\section{IELTS Test Preparation in Bangladesh}

According to the National Education Policy 2010 (NEP 2010) of Bangladesh, learning English is a sine qua non of academic and professional development to create a knowledge-based society and economy (Ministry of Education, 2010). For this reason, NEP 2010 mandated English as a second language through its curriculum to align its national aspirations (Rahman \& Pandian, 2018). National Curriculum for English, 2012 (NCE 2012) also aligned its secondary and higher secondary curriculum in 2012 for English education in light of the NEP 2010. Nonetheless, there is a disconnect in the curriculum, classroom practice, and assessment in English education of Bangladesh (Ali \& Walker, 2014). This situation led post-higher secondary students to take preparatory courses or private tuition at coaching centres for the IELTS test. They are about 13,000 to 18,000 at least. Apart from British Council centres, there are many IELTS preparatory coaching centres. However, the exact number of these coaching centres is unknown. These centres have been growing in an unplanned way mainly in Dhaka and Chittagong regions, advertising themselves as offering help, often allure potential IELTS candidates guaranteeing overall IELTS band score of 7 or above (Kar, 2013). Although most of the English language experts in Bangladesh opine that the growth of IELTS coaching centres is the result of our loopholes in English education, they warn that IELTS coaching centres are doing more hoax than help. Some of the experts raised the question how the coaching centres could guarantee all the students a band score of 7 or above in just three months without knowing candidates' current linguistic knowledge and competence level (Kar, 2013).

Since the IELTS test is popularly used as a language test all over the world to take admission to the universities where English is the medium of academic instruction, it plays a crucial role in many people's lives and careers in Bangladesh. Furthermore, the IELTS test is a 'vanguard' for English language proficiency testing as well as a high-stakes test with the power to make a change in one's life because many academic institutions accept between $6.0 \quad-7.0$ individual band score (IELTS, 2016a). So, paltry performance in writing module can deter test-takers' dream to have access to those English speaking developed countries for better education, better jobs, and a better life (Moore, Stroupe \& Mahony, 2009).

Every part of the education process has political and economic influences on our lives and society, so does testing. Therefore, it is necessary to address the evaluation procedures of such large-scale tests on a 
regular basis to ensure that they meet professional standards and contribute to the further development of the test takers. This article is an attempt to critically comment on IELTS writing module in connection with the criteria of a proper language test and its assessment procedures on a global scale in the Bangladeshi context based on few existing literatures.

The critical analysis of the article shows the issues related to IELTS writing assessment and selection of topics that can impede IELTS writing test to achieve its greater Validity, Reliability, Practicality, Authenticity, and Washback in the Bangladeshi as well as similar ESL contexts.

\section{Background and Overview of the IELTS Test}

\section{Rubrics of a Proper Language Test}

In order to develop and design any type of language test, the main considerable prior thought is the reasons for the test to whom it is focused, what the caveats are, and why the test is useful. Now the question arises how can we know whether a test has usefulness in a particular context, no matter before or after, in developing or designing a language test? Therefore, from the beginning to the end of designing or developing an entire test, we can put forth a model of test usefulness as the basic underpinning for quality control of it. In this regard, Bachman and Palmer (1996) proposed three principles about the usefulness of a test:

a) Overall usefulness of the test is to be maximized rather than the individual qualities.

b) Individual test qualities cannot be appraised separately but on the overall usefulness of the test.

c) Usefulness and the appropriate balance among the different qualities of a test cannot be suggested overall but should be chosen for every specific testing situation.

As a language test, the IELTS test follows the above-mentioned principles for its usefulness. These principles about the usefulness of a proper test can be further measured by the five cardinal test qualities. These are validity, reliability, practicality, authenticity, and washback. Therefore, the IELTS writing test can be critically examined in consideration of the five cardinal test qualities mentioned by Brown and Abeywickrama (2010) in the context of Bangladesh as well as similar ESL contexts.

\section{The Significance of IELTS Writing Tasks and} its Assessment

It is necessary to explain the format of the IELTS writing test, its test-takers, and the process of conducting the test all over the world to open up the discussion in the Bangladeshi context. The IELTS writing test is a direct test of writing where tasks are communicative and contextualized incorporating recent developments in research of writing. It is also meant for the specific target group considering their purpose and necessity of the test (Uysal, 2010). Writing module is a crucial and significant section in the IELTS to be assessed accurately. It is challenging for the testers to assess writing tasks as it is not only subjective but also critical in comparison to the other three skills. IELTS writing test is a target-specific test where tasks are analytical and argumentative. The test is designed to specific target groups of people, such as potential international students seeking admission at Universities and the people attempting to undertake training, to have work experience, and to meet immigration requirements in an English speaking country.

For these reasons, the IELTS writing test has both academic and general training 
modules combining two tasks per module. For the task 1, in academic writing module, test takers are required to write a report of approximately 150 words on the basis of a given table, chart or diagram, and for the task 2, candidates need to write an essay or a general report of about 250 words addressing an argument or a problem. Like academic writing module, task 2 remains the same for the test-takers of both general training and academic writing module. However, the task 1 is different which requires the candidates to write a letter responding to a given problem. Both the tasks of writing module must be completed within 60 minutes (IELTS, 2016b).

Trained and certified IELTS assessors separately evaluate each writing task giving more weight to the task 2 in marking than to the task 1. After testing, writing scores and the scores of the other three skills are averaged to produce an overall band score. How the process of average is executed into band score is still remained a secret. There is no pass or fail demarcation in IELTS. The performance of the test is described using 1 to 9 IELTS bands and the performance descriptors. The final band score is reported as an integer and half bands (Uysal, 2010).

\section{Bangladeshi Test-takers' Performance in IELTS Writing Module}

In recent time, the word 'IELTS' is being considered a household name among those who are inclined to study in anglophone countries or to emigrate there as a skilled migrant. Therefore, being a non-English country, both Bangladeshi students and emigrants-to-be need IELTS score as a means of English language competency. In Bangladesh, although English is not yet widely used by all walks of life in the society parallel to its first language 'Bangla' except for educational need and foreign communication, the latest NEP 2010 evaluated the English language as the tool to create a knowledge-based society (Ministry of Education, 2010) and mandated English as a second language through its NEC 2012. Rasheed (2012) and Hasan (2016) also posited that in reality, English is the second language of the country; and in many sectors and jobs, English is more important than Bangla - the first language of Bangladesh.

\section{The Main Focus of the Article}

The main focus of the article is to critically comment on the cardinal test criteria of IELTS writing module in connection with the Bangladeshi context and other similar ESL contexts. The discussion encapsulates both the strengths and weaknesses of the IELTS writing module for its alignment with cardinal test criteria and provides suggestions for further improvement of the IELTS writing module.

\section{Strengths, Weaknesses, and Recommendations Improvement}

\section{Validity to IELTS Writing Test}

Validity is the most complex in nature as an aspect of an effective test - and arguably the most essential part of a test (Brown \& Abeywickrama, 2010). According to Weir (2005), validity is a matter of degree of appropriateness of a test that should be evidenced in different matters concerned.

If a language test needs to have content validity, it must have the constitutions and representations of a sample of the language skill to measure with which it is meant to be concerned (Hughes, 2014; Mousavi, 2009). For example, if anyone attempts to assess a learner's speaking ability in a second language in a traditional setting by asking the learner to answer on paper-andpencil requiring grammatical knowledge, it lacks the content validity of a test. The 
IELTS writing task 1 , in terms of content validity, represents Target Language Use (TLU) content for both academic and general training module. Although the writing task 2 for both in academic test and general training module are descriptive as well as critical, we can compare it to university writing tasks. It is noticed that the task 2 of IELTS writing test is very much like a non-academic public form of discourse and do not match with any of the academic genres in the TLU domain. The academic assignments, for which the task is meant for, are mainly concerned much with practical research findings and relevant theoretical knowledge of the discipline and less with evaluative writing (Moore \& Morton, 1999). This situation may become worse for Bangladeshi students when they start their education at anglophone universities. Firstly, Bangladeshi IELTS test-takers achieve a low score in writing module compare to the other three modules. On top of that, the writing band score that many Bangladeshi IELTS test-takers obtain is not the actual projection of their writing skill. Nonetheless, they score 5.0 to 6.0 band score in writing module. More often they achieve that score by just following a stereotyped format to answer the writing tasks 1 and 2 advised by their respective IELTS coaching centres (Kar, 2013). Secondly, due to the lack of a process-based curriculum of English education in Bangladesh, students do not develop the critical and evaluative genre of writing skill. Therefore, to increase content-validity to Bangladeshi test-takers, it can be suggested that IELTS policy-makers can redesign both the task 1 and 2 in such a way that candidates cannot follow any set format to answer these tasks and they are forced to display their own critical writing skill. Furthermore, the task 2 of IELTS writing can be designed in a similar way to university assignment-writing and research-report-writing so that the task can align to the pragmatic purpose of the test for a candidate's future academic performance.

Moore and Morton (1999) explain that due to the diversity of the purpose and the targeted group of the test-takers, it is quite challenging to maintain construct validity of both General and Academic writing modules of the test for task response, lexical resource, and grammatical use and accuracy. For this reason, TLU tasks for its representativeness and relevance of the construct and meaningfulness of interpretations in other domains are indeed questionable as the tasks are only limited to British and Australian universities' context. Therefore, it is explicit that in respect of recognizing the construct validity of IELTS writing, other ESL contexts of English or global English have not been taken into consideration yet. Moreover, IELTS authority has set the scoring rubrics to assess the writing tasks 1 and 2. The measures of writing fluency (topic development, topic relevance, cohesion, and coherence), grammatical complexity, and language accuracy should be weighed equally. However, test-raters consider language accuracy first in comparison to writing fluency and grammatical complexity in scoring testtakers' writing band score (Azizi \& Majdeddin, 2014). This unequal weight of rating between writing fluency and language accuracy can be problematic in ESL contexts such as Bangladesh. Many of the prevalent Bangladeshi contextual expressions or collocations may seem grammatically inaccurate and culturally inappropriate in Anglophonic-context. In Bangladesh, for English education, the students (from Class-One to Class-Twelve) follow a textbook series for the whole country named English for Today - designed on the basis of local historical, social, contextual and cultural topics and written by the local non-native Bangali experts. Moreover, the aim of the English education in Bangladesh is not to introduce a British 
or American version of English but as a means of access to ICT, education, and global communication (NCTB, 2012). As a result, English textbooks included many socio-contextual topics. The socio-cultural context in Bangladesh is quite different from the Anglophone countries so does the common linguistic expressions. In Bangladesh, bumping on someone is duly apologized not merely by pronouncing 'sorry' as in the anglophone countries but also along with body language and surely with typical Bangladeshi or subcontinental collocation 'Extremely sorry' which is not common in anglophonic use. Similarly, some contextually common collocations or expressions - 'fresh water' instead of 'pure/clean or drinkable water','marriage anniversary' instead of 'wedding anniversary', 'dressing sense' instead of 'dress sense', 'quiz competition' instead of 'quiz' only, 'I saw a dream' instead of 'I had a dream' to mention a few are widely accepted and used by Bangladeshi user of English language. However, may seem weird to the native users as well as IELTS policy-makers. In ESL contexts like Bangladesh, although these aforementioned contextually generated expressions or collocations can communicate clearly, may seem 'lexically deviant' or 'inappropriate' to Anglophonic societies - are actually lexical innovations (Rahman, 1996) as we do not find identical meanings and exact substitutes often in Native English. Leitner (2004) further reinforces that many language features of L2 English are naturally innovated from L1 and L2 language-contact situations. Therefore, if the IELTS writing assessors do not attune their attitude to consider these contextual expressions as another variety of non-native English, the validity of the proper judgment of rating tasks' band score may be questioned. This issue should be addressed to increase the validity of IELTS writing assessment in Bangladesh as well as other ESL countries as each English language variety produces many idiomatic expressions rooted in its own culture. The absorption of these ESL idiomatic expressions will also increase mutual understanding of International English which is a global need now as Crystal (2003) calibrates that non-native speakers outnumbered native speakers by a ratio of 3 to 1 .

English has become either Lingua Franca or de facto first language (Crystal, 2003) and it is used as ESL in many countries to gain an extraordinary ground as an oft-used language. Considering this perspective, the IELTS test-takers have the valid ground to demand the inclusion of the global varieties and diverse cultural issues of English in the IELTS system of evaluation for its writing module. If this viewpoint is taken into cognizance, IELTS organizational body will have the opportunity to add meaningful and global dimensions to the test. Moreover, Riazi \& Knox (2010) posit that validity is crucial for the predictive power of the IELTS Academic Writing test as it is a global test for non-English test-takers. Uysal (2010) also criticizes that IELTS writing test drawing focus on validity issues, such as the definition of the 'international writing construct', without thinking about genres and different rhetorical conventions worldwide. This issue emphasizes the consideration of an accepted non-native variety of English language features of World Englishes. Therefore, the issue of standardization of non-native varieties in World Englishes has become debatable. For example, if IELTS organization starts considering non-native/ ESL writing genres of English in its assessment process, how the Bangladeshi variety of English or similar non-native varieties of English can be standardized to be accepted along with native varieties of English? Guzman and Rosario (2009) address this problem with reference to Philippine as non-native context: 
However, if the Philippine Variety of English (and other Asian varieties as well) is to be made acceptable in the academe and/or for academic purposes it likewise has to undergo a process of standardization, intellectualization and finally, codification. Again, one can never escape standards. (p.328)

As far as this standardization of ESL English is concerned, it is now a global call for the issue of international intelligibility of English writing. IELTS organization can gradually consider a Lingua Franca Core for its writing assessment. There is also criticism of the selection of topics as these are considered anglophonic and not sufficiently international or local (Moore, Stroupe \& Mahony, 2009). This issue may also reduce the validity of the IELTS writing test in ESL contexts. Therefore, one possible solution to the topic selections for IELTS writing tasks in ESL contexts such as Bangladesh, IELTS organization can select writing topics that have a global relevance rather than relevance to anglophonecontext only. As a result, the writing testtakers will have schemata of the IELTS writing topics resulting the test seem international to them.

\section{Reliability of IELTS Writing Test}

According to Hughes (2014), "Reliability is a measure of how consistent an assessment process is" (p.3). For example, if the variation of the test, time and its setting does not change test-takers' performance and the result remains the same or almost similar then it can be identified that the test is reliable. If it varies then the test has a paucity of reliability. Moreover, HampLyons (2002) describes that the writer, task, raters, and scoring procedure can reduce the reliability in a writing assessment as the sources of error. The IELTS has introduced few research efforts such as scoring procedure to reduce the chance of errors and to improve the acceptable reliability rates.

Reliability is an imperative quality for a test score. If the consistency of the test score does not comply with different time and setting, we cannot assure us with information on how to measure the ability we want for it. It is known that the IELTS writing test uses analytic approach to gauge the writing tasks based on set parameters for different band score. To calibrate the band score, the answer scripts of the IELTS writing tasks are examined not only by a single-rater but also by interraters for multiple judgments to ascertain the high reliability of the test. It is reasonably established that multiple judgments in writing assessment lead to such a score that is more akin to an objective score than any single judgment (Hamp-Lyons, 2002). This notion posits that the scoring process of the IELTS writing test has reliability.

Furthermore, both academic and general training module tasks are also aim-driven and serve the exact needs of test takers in terms of reliability. IELTS writing test acknowledges that the use of analytical scales contributes to higher reliability and to attain considerable difference across the band score. However, Mickan (2003) mentions the issue of inconsistency in ratings in IELTS writing exams and noticed that it was very tough to calibrate specific lexicogrammatical elements that separate different levels of performance. He also reveals that in spite of the use of analytic scales, raters inclined to respond to texts as a whole rather than to individual components. This finding actually ignites controversy about rater behavior in using the scale. Therefore, more precise information about the scale and about how raters determine scores from analytical categories should be given in detail to defend IELTS' claims about the analytic scales. 
The IELTS test also claims that it always tries to avert any bias or prejudice against any specific section of candidates of a particular cultural heritage in choosing the topics, or contexts of language for the writing task 1 and 2. However, in the ESL context such as Bangladesh, the IELTS writing module contradicts to its claim for reliability issue. Mickan \& Motteram (2006) reveal that the IELTS as a test of English proficiency was problematic because of "the fact that IELTS tests much more than English...it tests general knowledge, interpretation of statistics or graphs...critical thinking" (p. 43). It means that the IELTS test-takers should have not only proficiency in English but also general, critical, analytical, and interpretive skills of knowledge to attempt the writing tasks of the IELTS test. At the same time, they should have statistical knowledge too. Therefore, it may not be guaranteed if a test-taker is proficient in English writing only, can attain good band score unless he/she is equally good at statistical as well as critical and analytical skills of knowledge. This may pose a huge problem for the candidates of Bangladesh. They can face difficulties in providing exemplification to support a contextual opinion in writing task 2 for the lack of knowledge about the world beyond their context. Moreover, those who are not from scienceeducation background at their secondary higher secondary levels or do not have any statistical knowledge may also face problem answering the writing task 1.Arguably, this situation may be similar to other ESL contexts, especially in the excolonial countries of South, Southeast, and East Asia where the pattern of social dynamics for English education is identical (Bolton, 2008). Therefore, it is debatable whether the IELTS writing tasks are equally reliable to the test-takers of Arts, Social science and Humanities background. For this reason, Mickan \& Motteram (2006) admit that it is really challenging to control the topic variable by determining a common knowledge base for all the IELTS candidates. The IELTS test authority may conduct continuous research to overcome these reliability issues and to increase the appropriateness of topics for the writing module.

\section{Practicality in IELTS Writing Test}

To look into the degree of feasibility of an assessment procedure, practicality is a stand-point (Hughes, 2014). For example, if we raise the question: "are we capable of designing and developing a test in terms of cost, resources, and time?" If the answer is "yes" then it is perceived that the test has its practicality and if the answer denotes "no" that means the test is impractical or lacks practicality. Bachman and Palmer (1996) pointed out practicality as the yardstick to balance between the design, development, use of the test and the availability of required resources. As far as IELTS Academic and General modules are concerned, the test qualities for the practicality rubric in conducting the test internationally in terms of time, cost and the arrangements of resources.

To consider the practicality of the IELTS test for the time for the writing task 1 and 2, 60 minutes are given which is reasonable to answer the tasks. The test result is also published within two weeks of the test. So far the resources of the IELTS are to consider, it follows modern arrangements to conduct the test and the IELTS authority updates the resources and arrangements of the test accordingly. However, in terms of practicality in the IELTS test-taking in the ESL context in developing countries, the test is considered to be expensive for the testtakers (Moore, Stroupe \& Mahony, 2009). In Bangladesh, the fee for a regular IELTS test is $16,500 /-$ BDT (in the local c $u r r$ e $n$ c y ) ( h t t p s : / / www.britishcouncil.org.bd/en/exam/ ielts/dates-fees-locations) which is equivalent toAUD\$340. According to the Asian Development Bank(https:// 
www.adb.org/countries/bangladesh/ economy), GDP per capita in Bangladesh is 1, 517 US\$ with a low level of affluence.Being a low-GDP country, this is a huge amount for many lower and middleclass probable IELTS test-takers in Bangladesh.Therefore, it is recommended that the IELTS authority considers the test cost in proportion to the socio-economic condition of a developing country to increase its practicality for the test-takers.

\section{The Authenticity of the IELTS Writing Test}

Authenticity is one of the five major principles of language testing. Although the concept of authenticity is a bit tricky to define, Bachman and Palmer (1996) illustrated authenticity as "the degree of correspondence of the characteristics of a given language test-task to the features of a target language (TL) task" (p.23). Having an important effect on test-takers' perception about the test, authenticity gets a crucial consideration for language testing. The IELTS writing test also considers this factor for its writing tasks in the test for both the Academic and General modules, whether the test-takers are likely to correspond to the "real world' tasks or situations. It means, the test-takers can use their known knowledge to the tasks of the test to perform well in the test. However, in terms of the global ESL context, the IELTS test is Eurocentric for its expected 'world knowledge' for topic selection. The test clearly advantages European ESL testtakers than non-European test-takers. As a result, The IELTS writing topics fail to assess the actual writing skill of a non-Euro ESL test-taker who is inclined to be an applicant for either education or immigration in anglophone countries (Mickan \& Motteram, 2006). Therefore, there is a real need for the IELTS writing test to make an equal level playing ground for all ESL test-takers by mapping multiple sources of 'world knowledge' from both the Eastern and the Western world.

\section{Washback on the IELTS Writing Test}

According to Hughes (1989), washback can be defined as the impact of an assessment on teaching and learning either positively or negatively. As far as the washback of IELTS writing tasks is concerned to its testtakers or in the specific context, it can be identified as a high-stakes test with a universal standard for ESL participants. To measure their level of English through the test, being acclaimed as an International language test, the IELTS has a shortcoming in selecting and evaluating the tasks of writing as the tasks are based on the criteria which are basically depended on the anglophone writing norms rather than creating a dependence on the standard variety of 'World Englishes'. So, washback can take place if in choosing and judging the writing tasks, IELTS test authority doesn't consider task-topics from diverse ESL contexts. It is important to show the acceptance for other language variations (eg. in many ESL countries the continuous form of the verbs 'think', 'feel' in the sentences like "I am thinking", I am feeling" etc. are considered culturally correct and widely accepted which are not usual in Australian or British standard of English) and writing norms while rating for both the writing task 1 and 2 as they possess the rationale that the English language is nobody's language nowadays rather it is the language for everyone no matter what is the country or culture isas in some cases it is pidginized and in some cases it has become creole (Crystal,2003). In this regard, Kachru (1998) also states that the ownership of English lies with all those who use it (as cited in Hamid \& Baldauf, 2013, p. 477). Therefore, if the rating rubrics of the IELTS writing arerigidly followed by only the Australian or the British standard, it can create negative washback on IELTS writing test both for individuals and for the society of that specific ESL country. Moreover, as positive "washback' enhances intrinsic motivation (Brown \& Abeywickrama, 
2010), the exclusion of the other standards of English writing for the IELTS writing tasks, except the Australian or the British standard of English language, may also create negative Washback among the ESL test-takers.

\section{Overall Discussion}

Although the IELTS claims to reflect social and regional language variations in test input in terms of content and linguistic features, it actually includes only the varieties of the inner circle of English experts as the raters of IELTS written test. The non-native English experts are rarely attached to the process of IELTS test design and its content development. Moore, Stroupe, and Mahony (2009) in their research showed that out of six IELTS assessors in an ESL country, four were Australian, one was British and only one was Burmese (the people of Myanmar is called "Burmese"). So, IELTS test authority may include more non-native ESL experts from the top IELTS test-taking countries to provide the writing assessment process a global undertone.

Moreover, this notion narrows down its scope as an international test of English. As construct variation is identical to other language tests and the IELTS considers the need to account for language variation within the model of linguistic and communicative competence. Being an international English language test rater, it should encompass international language features in its construct definition to endorse that the IELTS can really measure English as an international language. Taylor (2002) also defines that in terms of cultural variations across the world, there are both micro-level linguistic variations and macro-level discourse variations. For this reason, IELTS writing test should evaluate the linguistic variations of English as well as the variations of rhetorical conventions and genres around the world to explain the writing construct to the criteria on coherence, cohesion, and logical argument. It is already evidenced that writing genre is not universal rather it is culture-specific (Riazi \& Knox, 2010). Consequently, people in different parts of the universe vary in consideration of their argumentative styles, logical reasoning, rhetorical norms, and organizational patterns of writing. Notwithstanding, it is convincingly evident that the host countries" trio partners of IELTS (British Council, IDP Australia, and Cambridge ESOL), have shown linguistic hegemony avoiding the above-mentionedissues and setting, i.e. inclusion of the culture-specific writing models as the only yard-stick, specifically for the task 2 of both academic and general writings. Moreover, due to the cultural unfamiliarity of the topics of the host countries, Bangladeshi students often struggle with the IELTS writing task 2. In this regard, Freimuth (2014) revealed that ESL test-takers were affected by 0.5 band score due to culturally unfamiliar topics of IELTS writing task 2. It means contextual issue can influence a test-taker's writing band score which emphasizes the importance of a contextual understanding of World Englishes as well as the relevance of global topics for IELTS writing tasks.

Since IELTS test authority globally assesses English for ESL countries, localized diversifications of English discourse that have their unique pragmatic bases should be recognized as Kachru (1985) explains, " In my view, the global diffusion of English has taken an interesting turn: the native speakers of this language seem to have lost the exclusive prerogative to control its standardization [...] What we need now are new paradigms and perspectives for linguistic creativity in multilingual situations across cultures" (p. 30). Kilickaya (2009) further adds, "English has currently seen the best option for communication among people from different language backgrounds, thereby 
being labelled as 'English as an International Language (EIL)' or 'English as a Lingua Franca'" (p.3). For this reason, although many of the corpora collected for corpus-based research of English language tended to follow British and American Englishes 15 years ago, the International Corpus of English (ICE) project found corpora that included other varieties of English, in particular, the Englishes of Outer Circle (Jenkins, 2007).For this reason, collocations in World Englishes and the aspects of native, as well as non-native varieties of English, again deserve to be investigated further by using International Corpus of English so that IELTS can be a bias-free test in consideration of English as a Lingua Franca for ESL countries.

IELTS may also consider more acceptable language variances in terms of style, task and context-based contents in its construct definition to provide more validity, reliability, and authenticity to the test and the test takers from all over the world. Considering the importance of these issues, more empirical researches can be conducted to find out the linkage of TLU tasks and IELTS test tasks in terms of their attributes not only in the domain of UK and Australia but also in other domains around the world. Therefore, one possible solution to the topic selections for IELTS writing tasks in ESL contexts such as Bangladesh, the concept of World Englishes is emphasized so that IELTS organization can select writing topics that have a global relevance. This issue can be one of the many reasons that influence the IELTS testtakers' low performance in writing module in Bangladesh which can direct to future research on the acceptability of Bangladeshi English in the IELTS writing assessment and the relevance of IELTS writing tasks in the Bangladeshi context. I assume this issue may also prevail in other similar ESL contexts and can be a potential area for the empirical research.

\section{Conclusion}

The article has highlighted a critical overview of the relevance and assessment of the IELTS writing tasks in the Bangladeshi as well as other probable ESL contexts. Any International Language Test of English should seem to be reliable and equal to all its test-takers. In the age of World Englishes, this may not be fair to consider only the native genre of English and its writing topics for the IELTS writing test without considering other non-native varieties of World Englishes. Today, the linguistic world of many people are becoming increasingly diverse, and the linguistic landscapes of individuals are not simply defined through physical space, but also through global travel, electronic space including media awareness and usage, popular culture, as well as the virtual space of the Internet. English in writing is exchanged probably more between nonnatives than the natives versus non-natives as three-quarters of the total mail is written in English by non-natives everyday (Davies \& Patsko, 2013). So, possibly there are situations in the IELTS host countries (UK, Australia, and NewZealand) where a significant percentage of the total population is non-native immigrants and international students from diverse ESL countries of the world. Therefore, in their written communication with other nonnatives, they presumably use their contextually owned but intelligible ESL writing norms. So, at present, it may not be reasonable to consider that the IELTS test is only conducted to assess the test-takers ability to use the English of the host countries. The IELTS authority may consider other ESL writing norms in its assessment procedure to acknowledge the unity of global English in diversity.

It may take time to codify the Bangladeshi L2 English of 170 Million people (excluding more than 10 million expatriates) as well as other ESL varieties of English in 
dictionaries and other authoritative publications but these features of English may gradually reach the larger social spaces via the continuous growth of International English genre with an estimated 1 billion L2 users where English is used either a second or foreign language (Crystal, 2003) and will nearly double by the year 2020 . Therefore, the discussion related to the cardinal test criteria and ESL contexts of English can be further explored empirically as the IELTS test has a global evaluative contribution and a global impact as an international test.

\section{References}

Ali, M., \& Walker, A. L. (2014). 'Bogged down' ELT in Bangladesh: Problems and policy. Investigating some problems that encumber ELT in an EFL context. English Today, 30(2), 33-38.

Azizi, M., \& Majdeddin, K. (2014). On the validity of IELTS writing component; Do raters assess what they are supposed to? Modern Journal of Language Teaching Methods, 4(1), 337352.

Bachman, L. F., and Palmer, A.S. (1996). Language testing in practice. Oxford: Oxford University Press.

Bolton, K. (2008). English in Asia, Asian Englishes, and the issue of proficiency. English Today, 24(2), 3-12.

British Council. (2016). IELTS.Retrieved from https://www.britishcouncil.it/ en/exam/ielts

Brown, H. D., \& Abeywickrama, P. (2010). Language assessment: Principles and classroom practices ( $2^{\text {nd }} e d$.). New York: Pearson/Longman.
Charge, N., \& Taylor, L.B. (1997).Recent developments in IELTS.ELT Journal, 51 (4), 374- 380.

Crystal, D. (2003).English as a global language (2nd ed.). Cambridge: CambridgeUniversity Press.

Davies, K.S.,\& Patsko, L. (2013, November 25). How to teach English as a lingua frankaELF. Retrieved from https:// www.britishcouncil.org/voicesmagazine/how-teach-english-linguafranca-elf

Freimuth, H. (2014). The influence of culturally unfamiliar IELTS writing prompts on student band scores: A case study. Perspectives (TESOL Arabia), 22(3), 5-11.

Guzman, M., \& Rosario, Y. (2009). How's my "English"? Philippine variety of English in the academe.In N. Othman \& S. Govindasamy (Eds.), English and Asia (pp. 323-30). Kuala Lumpur: International Islamic University Malaysia Press.

Hamid, M. O., \& Baldauf, R. B. (2013). Second language errors and features of world Englishes.World Englishes, 32(4), 476-494.

Hasan, S. M. M. (2016). The condition of English in Bangladesh: Second language or foreign language. Retrieved from http:// www.eslteachersboard.com/cgi-bin/ asia/index.pl?read $=158$

Hughes, A. (2014). Testing for language teachers (2 ${ }^{\text {nd }}$ ed. $)$ Cambridge: Cambridge University Press.

Hamp-Lyons, L. (2002). The scope of writing assessment.Assessing Writing, 8(1), 516. 
IELTS. (2016a). Retrieved from https:// www.ielts.org/teaching-andresearch/test-taker-performance

IELTS. (2016b). Retrieved from https:// www.ielts.org/policy/copyrightnotice

Jenkins, J. (2006). Current perspectives on teaching world Englishes and English as a lingua franca. Tesol Quarterly, 40(1), 157-181.

Kachru, B. B. (1985) Standards, codification, and sociolinguistic realism: the English language in the outer circle. In $\mathrm{R}$. Quirk and H.G. Widdowson (Eds.), English in the world: Teaching and learning the language and literature(pp. 11-30). Cambridge: Cambridge University Press.

Kar, A. (2013, May 04). IELTS preparation. The Daily Star. Retrieved from https:/ /www.thedailystar.net/news/ieltspreparation

Kilickaya, F. (2009). World Englishes, English as an international language and applied linguistics.English Language Teaching, 2(3), 35-38.

Leitner, G. (2004). Australia's many voices: Australian English - the national language. Berlin: Mouton de Gruyter.

Matin, R. (2014). History of IELTS. Retrieved from https:// w w w . linkedin.com/pulse / 20140721052816-262038053-historyof-ielts

Mickan, P. (2003). 'What is your score? An investigation into language descriptors from rating written performance'.IELTS Research Reports, 5(3),128-152.
Mickan, P., \& Motteram, J. (2006). The preparation practices of IELTS candidates: Case studies. Retrieved from https://www.ielts.org/ teaching-and-research/research reports/volume-10

Ministry of Education, Bangladesh. (2010). National education policy. Retrieved from http:/ / www.moedu.gov.bd/ on 10 December, 2015.

Moore, T. and J. Morton. (1999). Authenticity in the IELTS academic module. Writing test:A comparative study of Task 2 items and university assignments. IELTS Research Reports, 2, 74-116.

Moore, S., Stroupe, R., \& Mahony, P. (2009). Perceptions of IELTS in Cambodia: A case study of test impact in a small developing country. Retrieved from https://www.ielts.org/teaching-andresearch/research-reports/volume13

Mousavi, S. A. (2009).An encyclopedic dictionary of language testing (3rd ed.).Taiwan Tung Hua Book Company.

National Curriculum and Textbook Board (NCTB). (2012). National Curriculum for English. Dhaka: NCTB.

Rahman, A. M. M. (1996). Acceptability and English curriculum change in Bangladesh. In Robert J. Baumgardner (Ed.), South Asian English: structure, use and users (pp. 191-205). Urbana: Illinois University Press.

Rahman, M. M., \& Pandian, A. (2018). A critical investigation of English language teaching in Bangladesh: Unfulfilled expectations after two decades of communicative language teaching. English Today, 1-7. 
Rasheed, M.M.H. (2012). Learning English Language in Bangladesh: CLT and Beyond. Critical Literacy: Theories and Practices, 6 (2), 31- 48.

Riazi, A. M., \& Knox, J.S. (2010). An investigation of the relations between test-takers' first language and the discourse of written performance on the IELTS academic writing test, task 2. Retrieved from https:// www.ielts.org/teaching-andresearch/research reports/volume-16

Take IELTS test in or nearby Dhaka. (2018). Retrieved from https://www.ieltsexam.net/test-center-search / bangladesh/dhaka

Taylor, L. (2002). Second language writing assessment: Cambridge ESOL's ongoing research agenda. Research Notes, 16, 2-3.

Uysal, H. H. (2010). A critical review of the IELTS writing test.ELT Journal, 64(3), 314-320.

Weir, C. J. (2005).Language testing and validation: An evidence-based approach. Basingstoke, England: Palgrave Macmillan.

\section{Contributor}

S M Akramul Kabir is an Assistant Professor of English under the Directorate of Secondary and Higher Education, Bangladesh. He is currently pursuing his PhD in Education at the University of Canterbury, New Zealand. His areas of research interest include listening skill for language education, learning theories, and ICT in language education. 